\title{
AGUILERA, Mario (2014) Contrapoder y Justica Guerrillera. Fragmentación política y orden insurgente en Colombia (1952-2003). Bogotá: IEPRI.
}

\section{Diego Mauricio Fajardo Cely}

El estudio del conflicto colombiano se ha abordado desde diversos acercamientos, la historia de los actores sociales y políticos, sus estrategias, las políticas del Estado para confrontar a sus adversarios, etc. Aguilera propone la arista del acercamiento a su comprensión histórica a través del estudio crítico de las diferentes formas y desarrollos de contrapoderes en el territorio nacional, órdenes sociales, políticos y militares, que confrontan la institucionalidad estatal fragmentando su soberanía. Esta mirada que contempla el análisis de las diferentes estrategias insurgentes, en una dimensión histórico-espacial es una de las materias menos abordadas por la historiografía colombiana referente al conflicto armado, allí ha prevalecido la revisión histórica de los planteamientos político-ideológicos de las guerrillas y de sus desarrollos internos frente a temas como orden militar, estructuras, presencia de frentes, relaciones con movimientos sociales y políticos, el papel de la mujer a su interior y sus apuestas y posturas en los procesos de paz.

De esta manera el trabajo de Contrapoder y Justicia Guerrillera, aparece como uno de los primeros aportes al debate historiográfico frente al planteamiento estratégico de la insurgencia y su desarrollo histórico en términos políticos y territoriales, elemento que entre otras contempla la disposición de sus propias fuerzas en términos políticos, militares y espaciales, y su interacción con la población civil. Quizá otros de los aportes importantes a este tema son los desarrollados por el General retirado Carlos Ospina Ovalle La derrota de las $F A R C^{1}$. Que analiza la estrategia militar de la guerrilla y la forma en que las FFAA lograron controvertirla, y el de Andrés Peñate El sendero estratégico del ELN: del idealismo guevarista al clientelismo armado². Trabajos que sin embargo, resultan poco profundos y limitados frente a dimensiones históricas de mayor duración.

La legitimidad del Estado aparece en el trabajo de Aguilera como problema complementario a su incapacidad y debilidad para controlar el territorio nacional, presentando un acercamiento al problema más allá de la presencia institucional en

\footnotetext{
* Sociólogo de la Universidad Nacional. Tesista de la Maestría en Historia de la misma universidad. Otras reseñas publicadas son Basta ya. Memorias de Guerra y Dignidad en la Revista Historia y Sociedad de la Universidad Nacional sede Medellín.

1 OSPINA Ovalle, Carlos Alberto La derrota de las FARC. Regional Insigths. Center For Hemispheric Defense Studies. No. 5 marzo 15 de 2008.

2 PEÑATE, Andrés. (1999) El sendero estratégico del ELN: del idealismo guevarista al clientelismo armado. En Malcom y María Victoria Llorente (comps.). Reconocer la guerra para construir la paz, Bogotá. Norma/Uniandes/CEREC.
} 
el territorio, aporta elementos analíticos como el desarrollo histórico de las estrategias político-militares guerrilleras, su histórica intención de presentarse como un nuevo poder que le permite en sus retaguardias y zonas de disputa relaciones particulares con la población, mediadas por la oferta de bienes sociales y la garantía de respaldo social y político, así la justicia guerrillera, aparece como eje de la relación, y como lente analítico. Las discusiones académicas han sido más proliferas frente a estos temas, distintos autores han buscado analizar las diversas relaciones entramadas entre los grupos guerrilleros y la población donde hacen presencia, relaciones muchas veces orientadas por tipos de derecho alternativos, construidos histórica y conjuntamente entre actores armados y comunidades dando origen a justicias populares. Allí resultan ilustrativos los trabajos de Merry y Nicolás Espinosa, Una clasificación de la justicia popular ${ }^{3}$ y El campo jurídico del "otro derecho" en la Sierra de la Macarena 4 respectivamente. E incluso podríamos remitir la discusión a trabajos anteriores del propio Aguilera como Guerrillas y población civil. La trayectoria de las FARC 1964-2013, y La justicia de los contrapoderes, trabajos que resulta un esbozo de la presente investigación.

Cinco capítulos componen el texto. El marco temporal tomado para el estudio va desde los inicios de la justicia insurgente en la Violencia, hasta el inicio del repliegue de las Fuerzas Armadas Revolucionarias de Colombia (FARC) en 2003. El primer capítulo, busca dar respuesta a la pregunta: ¿Qué permite el surgimiento de los contrapoderes en los conflictos armados? Aguilera recurre a cinco variables para acercarse al problema: 1 . Una experiencia político-militar que busca resolver problemas prácticos de la guerra 2. Limitaciones o incapacidades del Estado para controlar su territorio 3. Intercambio entre insurgentes y comunidades, donde se transa un contrato social implícito, mediado por el intercambio de bienes sociales y la aceptación o respaldo político entre las partes 4. Desarrollo ligado a ideologías, y experiencias de guerra, orientadas en la idea marxista del poder dual 5 . Reconocimiento por la comunidad internacional y/o del Estado del status de beligerancia.

Las estrategias marxistas (insurreccional y GPP) son revisadas a la luz del planteamiento bolchevique de dualizar el poder y de los procesos revolucionarios de Rusia y China, paradigmáticos en la construcción de contrapoderes en las guerras revolucionarias; el proceso nicaragüense, salvadoreño y peruano son leídos bajo esta óptica, ubicándolos como dobles poderes en territorios selváticos,

\footnotetext{
3Merry, Sally Engle. Una clasificación de la justicia popular. En: El otro derecho. No. 30. Bogotá, 2003.

${ }^{4}$ Espinoza Nicolás. El campo jurídico del "otro derecho" en la Sierra de la Macarena. Elementos para un análisis crítico de la justicia alternativa en una zona de fuerte conflicto armado, en Revista Colombiana de Sociología, Vol. 32, No.2, Julio-Diciembre de 2009.
} 
mientras el ERP argentino y los Tupamaros uruguayos lo son bajo la idea de contrapoder sin territorios. El capítulo es un marco general para abordar los contrapoderes en el conflicto colombiano, aclarando la relación con otros procesos latinoamericanos y las estrategias de guerra insurgente, valiéndose de una tipología ubica los contrapoderes débiles y marginales, expresados en contrapoderes germinales, de resistencia y sin territorios. Por otro lado, las retaguardias nacionales y de frentes guerrilleros y sus contrapoderes; así, mientras los primeros suelen estancarse o desaparecer ante la ausencia estratégica, los segundos orientados por una estrategia que contempla prácticas judiciales hacia sus combatientes y hacia las comunidades como recurso políticomilitar, buscan consolidarse o expandirse. El autor se apoya en Jean Carbonier y su concepto de derecho múltiple o heterogéneo, que sustenta la idea de varios sistemas de justicia independientes o rivales en un mismo tiempo y espacio ( $p: 10)$.

Tres experiencias históricas se analizan en el segundo capítulo en un esfuerzo por presentar en la larga duración escenarios de contrapoder que conllevan fragmentaciones de la soberanía como constate nacional. La primera en los orígenes republicanos y en las guerras civiles del siglo XIX, la insurrección comunera, el proceso independentista y la Guerra de los Mil Días son las principales expresiones de estos fenómenos, siendo el gobierno de Viotá en esta última la primera experiencia de institucionalidad contra estatal. La segunda y tercera experiencia, se desarrollan en el contexto de la Violencia (1946-1965) donde liberales y comunistas organizan guerrillas de autodefensa o resistencia que confrontan al Estado. La experiencia liberal desarrolla un orden social hacia la población civil enmarcado en las Leyes del Llano donde Aguilera advierte el surgimiento de un Estado opositor insurgente y la idea de configurar una zona liberada ( $\mathrm{p}: 151)$. Por su parte, la experiencia comunista de autodefensa y guerrilla, desarrolló instrumentos y disposiciones para regular la vida de las comunidades; promoviendo formas alternativas de resolver los conflictos desde tribunales populares, promoviendo prácticas seculares y nuevas representaciones políticas, sanciones frente a las tradiciones religiosas, jurídicas, familiares, etc.

Los capítulos 3-5 son el estudio de los contrapoderes originados bajo la inspiración estratégica marxista orientadora de las insurgencias colombianas desde los 60, el sistema de justicia implementado al interior de estos escenarios es el eje análisis que permite encontrar un hilo conductor en el texto. Aguilera presenta una realidad histórica que varía conforme a inclinaciones ideológicas, modelos estratégicos, espacio geográfico y temporal.

El contrapoder germinal y la justicia ejemplarizante (1964-1974) son el tema del tercer capítulo, correspondientes a los momentos y zonas de asentamiento inicial de las guerrillas marxistas. Esta forma de contrapoder es entendida como 
una frágil articulación con las comunidades campesinas limitada a lo necesario para la supervivencia del grupo armado, lo que lleva a sustentar el contrapoder en dinámicas más coercitivas que concertadas; las tres experiencias guerrilleras (ELN, EPL y FARC) se dan como marginales en lo territorial y con cierto predominio de las dinámicas militares, sin embargo, las FARC a diferencia de las otras surge con expresión de un movimiento social de la época.

La justicia como medio disciplinante al interior de las guerrillas y como dinámica de relacionamiento con la población civil, se ha constituido en recurso histórico de implantación en territorios y comunidades. En este periodo los proyectos guerrilleros construyeron modelos de justicia, que buscaban crear órdenes sociales y contrapoderes locales con seguridad para sus propios grupos. El Ejército de Liberación Nacional sustentó su ejercicio de justicia en una modalidad defensiva donde primo lo penal, sancionó lo "potencialmente desestabilizador" del proyecto revolucionario, equiparó campesino con combatiente. Por su parte el Ejército Popular de Liberación emulando la experiencia china desarrolló un modelo de justicia comunitaria en el Alto Sinú y el Alto San Jorge, ubicándose como fuerza coactiva de las disposiciones de las Juntas Patrióticas, espacios auspiciados por la guerrilla donde la comunidad emitía normas y tramitaba conflicto de la vida de las poblaciones campesinas. Las FARC por su parte se mostró fuerte y en expansión recurriendo a la justicia expedicionaria, como medio para ofrecer seguridad a las comunidades, buscando expandirse por medio de la "limpieza social".

Una nueva forma de pensar el contrapoder, la violencia y la justicia guerrillera se expresó durante el periodo de 1976 y 1986 gracias al desarrollo del Movimiento 19 de Abril (M-19), que influenciado por las guerrillas del cono sur busco dar a estos elementos una naturaleza retaliadora. Se construyó entonces al interior de todas las guerrillas, auspiciadas por sus propios debates y replanteamientos internos de los ochenta, la idea de abanderarse de las demandas y ataques contra el movimiento social, oficiando como vengadores de la clase obrera, enjuiciando, condenando y ejecutando sentencias contra verdugos y traidores del pueblo, lo que no significó el abandono de las prácticas de justicia del periodo anterior, pues todas las guerrillas empezaron a desarrollar los tres tipos de justicia.

Los principales debates que este tipo de violencia y justicia tuvieron que enfrentar vinieron de la propia izquierda, condenando las retaliaciones contra miembros de otras organizaciones a manos de la insurgencia (CRIC), rechazando todo tipo de violencia (MOIR) o su ejercicio individual, propio del vanguardismo (Bloque Socialista). Aguilera presenta una fuerte crítica a este tipo de justicia al considerarla un agravante antes que una solución a los problemas sociales, 
tendiente a frenar las reivindicaciones de los movimientos sociales y a reducir aún más los espacios democráticos. A lo que suma el señalamiento como un causante del fuerte proceso de represión, estigmatización, tortura y asesinato por las Fuerzas Armadas de un gran número de líderes sociales y políticos.

El capítulo más extenso y quizá el de mayor aporte al debate académico, aborda la reconstrucción histórica del proceso de construcción del contrapoder y las modalidades de justicia implementadas por las dos principales insurgencias hoy activas en Colombia. Aguilera presenta las dinámicas de las dos retaguardias nacionales y de uno de los frentes emblemáticos de cada insurgencia durante 1985 a 2003. La posibilidad de constituir las retaguardias nacionales se da en el marco de profundas trasformaciones internas que se conjugan con cambios a nivel social y político a nivel nacional e internacional.

De esta manera, los replanteamientos estratégicos que para el ELN se van a dar en sus tres primeros Congresos $(86,89$ y 96) y lo van a ubicar en la estrategia del poder popular, son contemporáneos a los desarrollados por las FARC que en su VII conferencia (1982) va a elaborar su Plan Estratégico o Plan por la Nueva Colombia revalorado en los Plenos del Estado Mayor de 1989 y en la VIII Conferencia (1993), ubicándose en un modelo estratégico mixto. Cambios estratégicos que coinciden con modificaciones políticas como la descentralización política del Estado y con el reflujo del movimiento obrero y campesino, ubicando la necesidad de insertarse en la disputa del poder local, en la conducción del movimiento cívico y en la disputa en el territorio urbano.

Cinco elementos aparecen como marco general de las retaguardias: 1.Las FARC desarrollaron una retaguardia más eficiente desde la perspectiva de guerra contra el Estado. Una retaguardia más cercana al centro administrativo, desarrollaron ventajas geográficas construyendo corredores hacia el centro del país, tenían allí un fuerte poderío militar y un mayor control territorial comparada a la debilidad de la del ELN. 2. Las FARC a la vez que desarrollaron un control territorial de la retaguardia lograron desarrollar un control sobre los recursos necesarios para la guerra. En parte por los ingresos de la coca, mientras que el ELN se ubicó en zonas donde privilegió la extorsión petrolera, la minería y el secuestro. 3. Las FARC articularon las zonas de retaguardia al plan estratégico. Mientras el ELN no tuvo tan clara esta perspectiva estratégica privilegiando lo local y regional. 4. Ambas organizaciones buscaron construir contrapoderes basados en las organizaciones campesinas particularmente en las Juntas de Acción Comunal. 5. En las zonas de retaguardia frecuentemente se articulan y sobreponen la justicia comunitaria y la guerrillera. Articulación dada sobre las organizaciones campesinas y las JAC. 
La retaguardia de las FARC ubicada en los departamentos del Meta, Caquetá, Guaviare y Putumayo es presentada temporalmente de la siguiente manera: 1. Continuidad de la ocupación territorial y precariedad de la presencia estatal (1950-1975) articulada a la colonización 2. Irrupción del narcotráfico y de la guerrilla (1976-1992) y la disputa por el control territorial 3. Coexistencia del orden estatal y guerrillero (1993-2002) y la agudización del conflicto y 4. Recuperación de la ofensiva estatal (2002-2006). Esta retaguardia se caracterizó por las diferentes ofertas sociales de la guerrilla, mientras buscaba compartir el ejercicio de justicia con las comunidades, entregando a las JAC la administración de la justicia y la resolución de los conflictos. Así, mientras la insurgencia ofrecía seguridad, carreteras, préstamos, regulación en el mercado de la coca, etc.; las Juntas y sus comités regulaban la vida en los territorios, resolvían problemas de linderos, convivencia, etc., generalmente en consonancia de las orientaciones guerrilleras, plasmadas en disposiciones como la denominada popularmente ley de Bolívar.

Por su parte la retaguardia del ELN ubicada en la franja horizontal del Bajo Cauca Antioqueño, sur de Bolívar, Santander, sur de Cesar y Norte de Santander se dio como un espacio donde busco plasmar sus apuestas de poder popular, entregando mayor autonomía a las comunidades y sus organizaciones a la vez que promovía dinámicas anticapitalistas en el plano de lo económico; allí, acorde con su estrategia busco desarrollar formas de justicia alternativa como los "tribunales populares" y formas distintas de regular el orden social y la vida cotidiana de las comunidades, en cuya empresa opero la Constitución Campesina desarrollada y aprobada por 18 veredas en Santander hacia 1992.

Las retaguardias de frentes corresponden al Domingo Laín por el ELN (FDL) y el Frente 29 para las FARC, frentes emblemáticos para cada organización. Mientras el FDL se sustentó en los recursos petroleros y en una fuerte y amplia base social que le permitió incluso llegar a mantener un fuerte contrapoder en Arauca, notorio hasta hoy, el Frente 29 lo hizo en el control sobre el narcotráfico desarrollando un importante corredor estratégico, sin lograr la misma fuerza en el contrapoder que el FDL, proporciono justicia y veeduría armada, pero no logro dotar de autonomía relativa a la justicia comunitaria ni a los procesos sociales, privilegiando lo militar sobre lo político. La fiscalización de los dineros públicos como práctica común, llevo al juicio, retención y asesinato de varios alcaldes y funcionarios locales. La justicia ejercida por ambas insurgencias tanto en sus retaguardias fue percibida como una justicia más ágil, barata y en cierto modo clasista, lo que indicaría una inclinación por los pobres. Percepción que le permitió mantenerse en los territorios, a pesar, incluso de la existencia de la justicia estatal, llegando por momentos a complementarse. 
En las zonas de disputa se dio la continuidad del carácter ejemplarizante, castigando delincuentes, auxiliadores del paramilitarismo o el Ejército y, haciendo veeduría armada a funcionarios públicos. Sin embargo, en algunos territorios las justicias se vieron superpuestas, así la justicia guerrillera se vio en tensión o complementariedad con la estatal, comunitaria, paramilitar e incluso con otro grupo guerrillero. Ambas apuestas insurgentes buscaron a partir de la década del 90 presentarse como estados paralelos que reclamaban para sí el status de beligerancia. Las FARC dicto leyes en sus territorios e incluso proclamo la existencia del Estado Independiente de las FARC (2002) luego del derrumbe de la Zona de Distención, expresión más cercana a dicha iniciativa. Por su parte el ELN busco hacerlo en su apuesta de Convención Nacional y el reclamo de una Zona de Encuentro en su retaguardia para negociar con el gobierno Pastrana. Sin embargo, la vuelta a la ofensiva militar del Estado bajo los planes militares Colombia, Patriota y Consolidación- los dos últimos en el gobierno de Uribe- y el avance paramilitar desarticuló las zonas de retaguardia hacia finales de los $90 \mathrm{y}$ obligando el repliegue guerrillero.

El texto de Aguilera es continuidad de un proceso investigativo presente en trabajos y artículos que toman allí mayor concreción. Un texto que va y viene sobre el tema central, complementándolo y presentando nuevas aristas en un debate pertinente y por demás necesario para el momento histórico de nuestro país. Si bien, el estudio de los contrapoderes en el conflicto colombiano significa un aporte y a la vez un reto a la investigación histórica, que para este caso cuenta con un gran recurso de fuentes, la reflexión debe ser profundizada. Ideas como el cuestionamiento a la justicia retaliadora como limitante de la movilización social, su asimilación a la justicia estatal, la financiación guerrillera a partir del narcotráfico, y el estancamiento militar de estas, deben ser profundizadas y matizadas a partir de las diferentes experiencias históricas. Sumado a lo anterior la reflexión del autor frente a las experiencias de las retaguardias se haya desbalanceada presentando una mayor elaboración en el caso de las FARC y dando menor espacio al ELN, allí poco se atiende por ejemplo a la incursión paramilitar en su desarticulación; a lo que valdría la pena agregar la necesidad de sobrepasar la metodología del caso emblemático para dar cuenta de las retaguardias de frentes, permitiendo ver un panorama diverso al interior de cada organización. 